\title{
Nodule on the Neck
}

\author{
Malan Kern, MD; Kelsey Parks, BS; Henry K. Wong, MD, PhD
}

\section{Eligible for 1 MOC SA Credit From the ABD}

This Photo Challenge in our print edition is eligible for 1 self-assessment credit for Maintenance of Certification from the American Board of Dermatology (ABD). After completing this activity, diplomates can visit the ABD website (http://www.abderm.org) to self-report the credits under the activity title "Cutis Photo Challenge." You may report the credit after each activity is completed or after accumulating multiple credits.

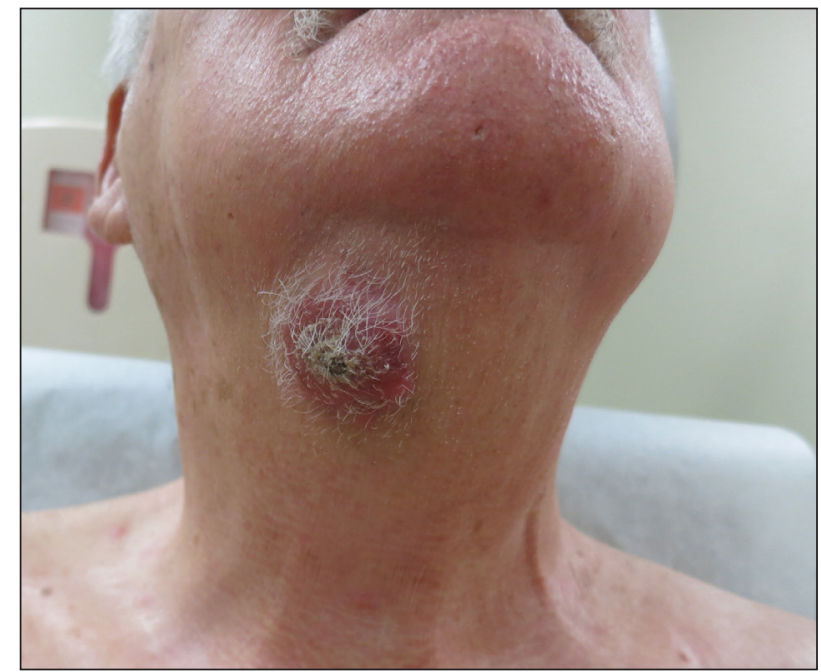

An 80-year-old man presented to our clinic with a large lesion on the right upper neck of approximately 4 weeks' duration. He reported that it was rapidly increasing in size and had bled on several occasions. No treatments were attempted prior to the initial visit. He denied any constitutional symptoms. The patient had a history of nonmelanoma skin cancers but no other chronic medical problems. Physical examination revealed a large, $35 \times 40-\mathrm{mm}$, erythematous nodule with central ulceration and overlying hyperkeratosis on the right upper neck. No palpable cervical, supraclavicular, or axillary lymphadenopathy was observed. An excisional biopsy of the lesion was obtained.

\section{WHAT'S YOUR DIAGNOSIS?}
a. atypical fibroxanthoma
b. basal cell carcinoma
c. keratoacanthoma/squamous cell carcinoma
d. Merkel cell carcinoma
e. primary cutaneous anaplastic large cell lymphoma

PLEASE TURN TO PAGE 253 FOR THE DIAGNOSIS

From the University of Arkansas for Medical Sciences, Little Rock. Drs. Kern and Wong are from the Department of Dermatology, and Ms. Parks is from the College of Medicine.

The authors report no conflict of interest.

Correspondence: Malan Kern, MD, Department of Dermatology, University of Arkansas for Medical Sciences, 4301 W Markham, Slot 576, Little Rock, AR 72205 (mkern2@uams.edu).

doi:10.12788/cutis.0244 


\section{THE DIAGNOSIS:}

\section{Primary Cutaneous Anaplastic Large Cell Lymphoma}

M icroscopic analysis showed a dense proliferation of mononuclear cells filling and expanding the dermis with focal epidermotropism (Figure 1). Immunohistochemistry demonstrated strong and diffuse staining for CD3, CD4, and CD30 (Figure 2) and lack of staining for anaplastic lymphoma kinase (ALK). Workup to exclude systemic disease was initiated and included unremarkable computed tomography (CT) of the neck, chest, abdomen, and pelvis along with no abnormal cells on bone marrow biopsy. Complete blood cell count, basic metabolic panel, and lactate dehydrogenase were within reference range. Given the lack of evidence for systemic involvement, a diagnosis of primary cutaneous anaplastic large cell lymphoma (PC-ALCL) was made. The treatment plan for our patient with a solitary lesion was localized radiation therapy.

Primary cutaneous $\mathrm{CD} 30^{+}$lymphoproliferative disorders encompass a spectrum of conditions, with premalignant lymphomatoid papulosis (LyP) at one extreme and the malignant PC-ALCL on the other. ${ }^{1}$ The diagnosis of PC-ALCL is made by clinicopathologic correlation, and lesions typically present abruptly as solitary or grouped nodules with a tendency to ulcerate over time. Spontaneous regression has been reported, but relapse in the skin is frequent. ${ }^{2}$

A representative, typically excisional, biopsy should be performed if the clinician suspects PC-ALCL. Histologic criteria include a dense dermal infiltrate of large pleomorphic cells and the expression of CD30 in at least $75 \%$ of tumor cells. ${ }^{3}$ Primary cutaneous anaplastic large cell lymphoma typically lacks the $A L K$ gene translocation with the nucleophosmin gene, NPM, that is common in systemic disease; however, a small subset of PC-ALCL may be ALK positive

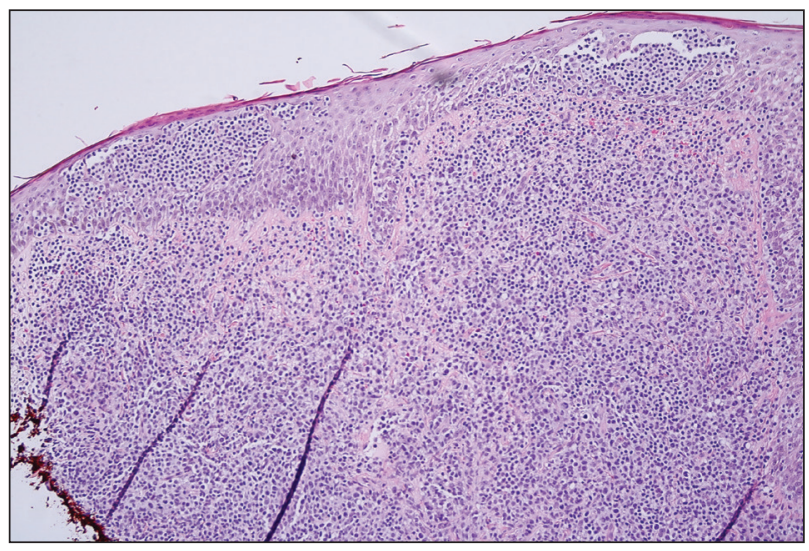

FIGURE 1. Dense proliferation of mononuclear cells filling and expanding the dermis with focal epidermotropism (H\&E, original magnification $\times 10)$. and indicate a higher chance of transformation into systemic disease. ${ }^{2}$

The extent of the lymphoma should be staged to exclude the possibility of systemic disease. This assessment includes a complete physical examination; laboratory investigation, including complete blood cell count with differential and blood chemistries; and radiography. A positron emission tomography-CT scan of the neck, chest, abdomen, and pelvis, or a whole-body integrated positron emission tomography-CT are sufficient for the radiographic examination. ${ }^{3}$

The initial choice of treatment for solitary or localized PC-ALCL is localized radiation therapy or low-dose methotrexate. Targeted therapy such as brentuximab has been shown to be effective for those with multifocal systemic involyement or refractory disease. ${ }^{2}$ Cure rates from radiation therapy alone approach $95 \% .^{3}$ It is important to highlight radiation therapy as the initial management plan to increase awareness and to avoid inappropriate treatment of PC-ALCL with traditional chemotherapy.

Large lesions of LyP may appear similar to PC-ALCL on histopathology, making the two entities difficult to distinguish. However, in contrast to PC-ALCL, LyP classically has a different clinical course characterized by waxing and waning crops of lesions that typically are smaller $(<1 \mathrm{~cm})$ than those of PC-ALCL. ${ }^{2}$ Large cell transformation of mycosis fungoides is another entity to consider, but these patients usually have a known history of mycosis fungoides. ${ }^{4}$

Keratoacanthomas, considered to be a variant of a well-differentiated squamous cell carcinoma, present as rapidly enlarging crateriform nodules with a keratotic core. They usually are found on the head and neck or sun-exposed areas of the extremities and may regress

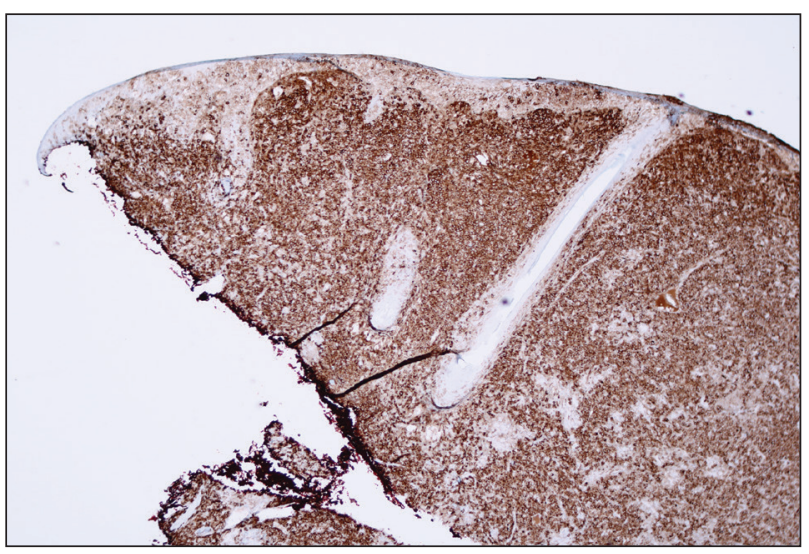

FIGURE 2. Immunohistochemistry showed strong and diffuse staining for CD30 (original magnification $\times 40$ ). 
spontaneously. ${ }^{5}$ Histology will show atypical, highly differentiated squamous epithelia. Merkel cell carcinoma also has a predilection for the head and neck in older patients and may present as a rapidly growing nodule. However, histology will show an aggressive tumor with small round blue cells, and immunohistochemistry will show the characteristic paranuclear dot staining for CK20 along with staining for various neuroendocrine markers. Similarly, atypical fibroxanthoma is a low-grade sarcoma that also presents on the head and neck of elderly sun-damaged patients. ${ }^{5}$ Histology will show dermal proliferation of spindle cells that often extend up against the epidermis along with pleomorphism and atypical mitoses. Basal cell carcinoma is a common tumor that can present on the head and neck in sun-damaged patients. Nodular basal cell carcinomas can enlarge and ulcerate, but growth is seen over years rather than weeks. $^{5}$ Histology characteristically will show tumor islands composed of basaloid cells with peripheral palisading and clefting between the tumor islands and the stroma.

\section{REFERENCES}

1. Swerdlow SH, Campo E, Pileri SA, et al. The 2016 revision of the World Health Organization classification of lymphoid neoplasms. Blood. 2016;127:2375-2390.

2. Brown RA, Fernandez-Pol S, Kim J. Primary cutaneous anaplastic large cell lymphoma. J Cutan Pathol. 2017;44:570-577.

3. Kempf W, Pfaltz K, Vermeer MH, et al. EORTC, ISCL, and USCLC consensus recommendations for the treatment of primary cutaneous CD30-positive lymphoproliferative disorders: lymphomatoid papulosis and primary cutaneous anaplastic large-cell lymphoma. Blood. 2011;118:4024-4035.

4. Jawed SI, Myskowski PL, Horwitz S, et al. Primary cutaneous T-cell lymphoma (mycosis fungoides and Sézary syndrome): part II. prognosis, management, and future directions. I Am Acad Dermatol. 2014;70:223.e1-17.

5. Bolognia JL, Jorizzo JL, Schaffer JV. Dermatology. 3rd ed. Saunders Elsevier; 2015:475-489. 